\title{
Pre and post-migration determinants of socio-cultural integration of African immigrants in Italy and Spain
}

\author{
T. Fokkema \\ H. de Haas \\ December 2015
}

\begin{abstract}
Using a unique dataset $(N=2,014)$, we examine the pre and post-migration determinants of socio-cultural integration among first-generation immigrant groups in southern Europe: Moroccan and Senegalese migrants in Spain and Egyptian and Ghanaian migrants in Italy. The results of the pooled and immigrant-group specific regression analyses are partly highlight the dominance of pre-migration factors. Immigrants who were welleducated and well-informed prior to migrating and who migrate at a young age achieve higher levels of socio-cultural integration. Going against hypotheses found in the literature, female gender and North African origin have a positive effect on socio-cultural integration as opposed to male gender and sub-Saharan origin. With regard to post-migration factors, occupational status is the main economic determinant of socio-cultural integration.

Interestingly, being employed as such has no significant effect on socio-cultural integration. The results suggest that policies allowing immigrants to benefit from the human capital they carry across borders and achieve upward socio-economic mobility are also likely to have an enhancing effect on their socio-cultural integration.
\end{abstract}

Keywords: immigrant integration, first-generation, migration, Europe, sub-Sahara Africa, North Africa 


\section{Pre and post-migration determinants of socio-cultural integration among African immigrants in Italy and Spain}

\section{Introduction}

There is a long research tradition on the integration of immigrants into Western societies. While classical theoretical models of immigrant integration are largely based on research conducted among immigrant groups in the USA, they have also been applied and tested in northwestern Europe, where countries such as the UK, France, Germany, the Netherlands and Belgium have evolved into major settlement countries of new immigrant groups since the 1960s and 1970s (Givens 2007; van Londen, Phalet, and Hagendoorn 2007; van Tubergen, Maas, and Flap 2004). As there are major political and cultural differences among European societies, one of the most important contributions of European researchers to the international theoretical debate on immigrant integration has been to bring in the national context as an important determinant of integration. These results have shown significant differences in socio-cultural and economic integration of similar immigrant groups (e.g., Turks) in different European countries, which have been partly attributed to differences in educational systems, labor markets and integration policies (Crul and Vermeulen 2003; Doomernik 1998; Heckmann, Lederer, and Worbs 2001; Thomson and Crul 2007).

Micro-empirical research has yielded valuable insights in the importance of human capital factors (education, skills, work experience) as well as age and length of stay in the receiving countries in determining the economic integration of immigrants and their children (Chiswick \& Miller 2001, Crul \& Vermeulen 2003). In addition, macro level (social, economic, cultural 
and political) characteristics of societies of origin as well as migration motives have been increasingly recognized as important determinants of the immigrant integration. For instance, on the basis of a double comparative study in which the economic integration of immigrants from multiple origins was simultaneously studied in 18 Western countries, Van Tubergen et al (2004) concluded that politically motivated immigrants were less favorably selected and show a weaker labor market performance than economically motivated immigrants and that migrants moving over greater geographical distances have a higher chance to be employed, supposedly because they have more incentives to invest in specific human capital skills. They also found evidence corroborating discrimination theories that migrants from predominantly (supposedly culturally closer) Christian nations and migrants living in countries with leftwing dominated governments were more likely to be employed. They also concluded that exclusion of women from labor markets in origin countries tend to be replicated in destination countries.

The literature distinguishes a number of dimensions of integration processes, and a common distinction is between structural and socio-cultural integration. Structural integration pertains to the acquisition of rights and status within the core institutions of the receiving society, such as employment, housing, education, political and citizenship rights (Heckmann 2005). Sociocultural integration refers to the cognitive, behavioural and attitudinal changes in conformity to the dominant norms of receiving societies (cultural integration or acculturation); social intercourse, friendship, marriage and membership of various organisations (interactive integration); and feelings of belonging, expressed in terms of allegiance to ethnic, regional, local and national identity (identificational integration) (King and Skeldon forthcoming). 
The majority of previous studies on determinants of immigrant integration have focused primarily on structural (particularly economic and educational) integration and have increasingly focused on the second generation (Aparicio 2007; Meurs, Pailhe, and Simon 2006; Portes and Hao 2004; Simon 2003). Relatively less empirical research has focused on the determinants of socio-cultural integration of migrants and among recently arrived firstgeneration (i.e., foreign-born) migrants in particular. An improved understanding of the determinants of socio-cultural integration is relevant for our understanding of immigrant integration at large. First of all, although structural and socio-cultural integration into 'mainstream' society are often closely related and tend to reinforce each other (Dagevos 2001), we can not assume that this is a one-to-one relationship. This is exemplified by immigrant or ethnic minority groups such as the Chinese where economic integration goes along with high maintenance of a strong group identity and resistance against assimilation. The other way around, immigrant groups may experience 'downward' assimilation into the mainstream lower class cultures while underachieving in education and on job market (Portes 2007) The exact nature of the interlinkages between socio-cultural and structural integration still remains somehow underexplored, and merit more empirical work, particularly in the European context.

This question is also relevant in the light of increasing concern in political and scholarly debates on social cohesion, in which a perceived lack of socio-cultural integration among some immigrant groups has received increasing attention. The idea is that immigration and too much ethnic diversity reduce social solidarity and social capital (Putnam 2007). However, such debates tend to reduce integration to a largely cultural and attitudinal issue - as a matter of personal choice of migrants - with a concomitant neglect of how such socio-cultural integration might constrained by contextual constraints impeding structural integration, such 
as discriminatory policies, racism and other exclusion mechanisms. An improved understanding of the personal and structural determinants of socio-cultural integration can also lead to improved insights in the way policies shape such integration processes.

Besides the lack of empirical work which systematically explores the determinants of sociocultural integration, there is still a relative lack of studies that simultaneously study pre and post-migration contextual determinants of migrants' socio-cultural integration which go beyond individual background characteristics such as gender and education. There has been a particular lack of studies exploring how factors relating to the migration process itself affect migrants' socio-cultural integration, and what the relative importance of such factors is in comparison to post-migration determinants of socio-cultural integration, such as labor market participation and years of residence. Pre-migration factors, including migration motives, prior migration experience, age at time of migration, and the degree and type of information obtained prior to migration, are likely to affect immigrants' inclination to speak majority languages, feelings of belonging, the extent and nature of social interactions, and so on.

The relative lack of comprehensive empirical studies on the role of pre and post-migration factors in socio-cultural integration processes of immigrants in Europe is related to a lack of appropriate datasets. This study aims to fill part of that gap through an analysis of unique survey data collected among four African immigrant groups (Egyptians, Ghanaians, Moroccans and Senegalese) in Italy and Spain. This study aims to assess the pre and postmigration determinants of socio-cultural integration, as well as to explore explanations for differences among the four immigrant groups studied. In addition, this study provides new insights on African immigrant groups in new southern European destination countries, whose integration has rarely been studied so far. 
The focus of this paper is on first generation migrants because this allows us to study premigration integration determinants. Improved insight on the role of pre-migration factors in socio-cultural integration processes is also policy relevant. For instance, immigration policies tend to select migrants on certain individual characteristics (such as age, skills, education and income) and, hence, may indirectly affect integration processes. It is often assumed that relatively high skilled labor migrants are more inclined to "integrate", in particular in comparison with low skilled migrants often originating from rather traditional societies, who would be more likely to remain oriented on origin countries. However, the real question here is whether this perceived lack of structural and socio-cultural integration is linked to specific cultural traits, group characteristics or personal preferences or should rather be seen as the result of discrimination and other exclusionary mechanisms in receiving countries.

Before turning to the discussion of theory and hypothesis, it is important to mention that 'integration' is a highly contested concept. Although it is often contrasted to 'assimilation', the distinction between the two terms is more blurred in practice. As King and Christou recently argued (2007), integration and assimilation are terms of shifting and overlapping meaning, and subjects of a wide-ranging debate in the US, Europe and elsewhere.

Assimilation is more prominent in US debates where there has traditionally been a prevailing assumption towards a hegemonic American society based on erosion of ethnic roots. The concept of integration has been more favoured in European debates, reflecting normative models of a more multicultural or pluralistic society. However, operational definitions of integration often focus on adoption to majority society and culture, and are often virtually indistinguishable from assimilation. For instance, Heckman (2005:15; in King and Skeldon forthcoming) perceived integration as the "long-lasting process of inclusion and acceptance of migrants in the core institutions, relations and statuses of the receiving society". Although 
Heckman acknowledges that integration is an interactive process between migrants and the receiving society, he emphasised the receiving society has much more power and prestige. In a rather similar vein Portes (2008) stressed such asymmetries and therefore contested that migrants are generally unable to remake the 'mainstream', that is, to change the core institution and culture of society. King and Christou (2007) argued that such definitions do acknowledge not question the hegemonic role of receiving societies. Castles et al (2002) argue that in an open democratic societies people have different ideas about what constitutes the norm for that society. They therefore contact that there can be "just one mode of integration". Similarly, one can contest the notion of a singular, monolithic 'mainstream'. It is not the aim of this paper to indulge into this complex debate, but it is important to be aware of the contested, normative and politicized nature of the integration concept, which is less neutral than often assumed.

\section{Theory and hypotheses}

Neo-classical migration theory conceives internal and international migration as the result of spatial differences in (expected) wage levels (Harris and Todaro 1970; Todaro 1969), and largely disregards integration issues. Neo-classical models have been sophisticated by incorporating human capital theory (Becker 1962), in which migration is seen as an investment decision (Sjaastad 1962). Considering that individuals are different in terms of skills, knowledge, physical abilities, age, gender, and so on, there will also be differences in the extent to which people are expected to gain from migrating, that is, they can expect diverging returns on their "migration investment". Hence, we can hypothesise that the success of migrants on the labor market is affected by various directly observable (such as education, 
language command, work experience) and more difficult to observe factors (ability, motivation, and talent) (van Tubergen, Maas, and Flap 2004).

We can extend this hypothesis on economic integration to socio-cultural integration by drawing on insights from social capital theory (Bourdieu 1985; Portes 1998), assuming that human capital in the forms of knowledge and skills can also be used to acquire social capital, which can defined as "the aggregate of the actual or potential resources which are linked to possession of a durable network of more or less institutionalized relationships of mutual acquaintance or recognition” (Bourdieu 1985:284). More social capital, however, does not automatically mean being more integrated in receiving societies. The literature on social capital has distinguished closed and open networks as well as bonding and bridging social capital (Granovetter 1973; Putnam 2000). From this, we can infer that closed networks among migrant populations (bonding social capital) without strong social ties with native populations (bridging social capital) and other immigrant groups (the so-called ethnic bridges; see (Briggs and Souze 2003) hinder integration into 'mainstream' society.

This points to the "downside of social capital" put forward by Portes (1998), who criticized uncritical and fashionable applications of the concept, which tend to view social capital as wholly beneficial and naively assume that social capital can resolve the classic dilemmas of collective action. Portes stressed that social capital can also have possible negative implications. Membership of a community brings demands for conformity, which may be asphyxiating to the individual spirit, and tight social networks and obligations may undermine economic initiatives through pressing social obligations to support family and community members and tend to discourage establishing ties with outsiders. Although migrant networks are of great help in migrating, they may also to be exclusionary when it comes to integration 
into receiving societies. Yet, the empirical evidence is ambigious. For instance, some studies show that immigrant-group specific "bonding" social capital (migrant networks) can facilitate immigrants' economic and educational success, and therefore, their long-term economic and political integration in receiving societies in the longer term (Portes and Rumbaut 1990). Thus, initial orientation on members of the own immigrant group and origin societies (i.e., limited socio-cultural integration) can coincide with successful economic integration, especially in the longer run. The latter is also expected to lead to increased contacts with natives and a shift in cultural orientations, although we should not assume that total assimilation is the inevitable (or desirable) end point.

It is likely that, besides contextual factors, both skills achieved prior to migration and skills achieved after settling in the receiving society play a decisive role in the determining the type of social capital migrants acquire and, hence, in the level of socio-cultural integration. With regard to pre-migration characteristics, it is obvious to consider the level of education. It has been argued that high educated people generally have a more secular and open worldview (Kalmijn 1998). Highly skilled immigrants are also likely to experience less class and attitudinal differences with native-born populations and to face less discrimination.

We also expect that factors relating to the migration process itself determine the extent to which individuals are able and willing to invest in social relations with "natives" or other migrants groups. We assume that especially migration motives, the degree and type of information about receiving societies in advance, age at time of migration and prior migration experience affect the level of socio-cultural integration. Largely on the basis of human capital theory, we hypothesize that migrants whose migration was primarily economically motivated show higher levels of socio-cultural integration than those who migrated for relational or 
other reasons. We also hypothesize that migrants who were well-informed about the receiving society prior to settlement will be better prepared for their new living conditions and hence, will be better equipped to integrate socio-culturally. With regard to the nature of information, based on the distinction between bonding and bridging capital, we expect that migrants who mainly relied on informal information (obtained through family and networks) are more oriented towards migrant communities after arrival. Migrants who mainly relied on official information sources are expected to have more often migrated on their own, rely less on migrant networks, and will therefore be more inclined to relate to and identify with native populations. Finally, people who migrated at a young age or had migration experience before, are likely to be less socialized in their country of origin. Hence, we hypothesize a positive effect of migration at young age and prior migration experience on socio-cultural integration.

With regard to post-migration skills, three factors will be considered: work status, length of stay in receiving country and the intention to return or migrate to another country. There is ample evidence that, mainly due to technological process, migrants' lives and identifications have become increasingly transnational. Consequently, economic integration does not necessarily go along with complete assimilation or adoption of majority society norms, habits, lifestyles and identifications (Portes, Guarnizo, and Landolt 1999; Vertovec 2004). Nevertheless, we expect that labor force participation has a positive effect on socio-cultural integration. Migrants who work are more likely to have contact and identify with native workers, and this effect is likely to be more positive in higher occupational levels, were natives normally concentrate. This is likely to be a two-way causality. In addition, it is suggested in the literature that with the length of one's stay in the receiving country and the increasing determination to stay, immigrants become gradually become more integrated (Alba and Nee 2003). Hence, it is predicted that migrants with a longer period of residence and 
migrants who do not intend to return or migrate to another country, are more integrated socioculturally.

Also gender differences are likely to affect socio-cultural integration, where we can hypothesize that women from traditional, in particular those from "patriarchical" cultural backgrounds, are more likely to stay at home and be less present in the public space. Moreover, for fear of repercussions, women may be more likely than men to stick to behavior and traditions dominant in the origin countries (Remmennick 1999). Moreover, female migration from African countries is generally seen as mainly "dependent" family migration. From this, we hypothesize that female migrants are likely to be less integrated socio-culturally than male migrants, also when controlling for all other relevant factors.

In order to explain possible differences in socio-cultural integration according to origin countries in our sample, it is useful to consider geographical and cultural distance as relevant factors in explaining immigrant integration. Geographic distance is expected to increase skill selection and migration costs and to decrease the likelihood of return (Borjas 1987; van Tubergen, Maas, and Flap 2004). This all is expected to increase the incentives to invest in human capital (Chiswick and Miller 2001). The counter argument is that geographical distance also tends to coincide with greater cultural distance, for instance in terms of religion, language and sharing a colonial past or not, making it more difficult to relate to natives and to identify with majority cultures (van Niekerk 2007). The other way around, the social distance natives feel in relation towards immigrants and related prejudice and discriminatory practices are also likely to affect the extent of social interaction between natives and immigrants (van Tubergen, Maas, and Flap 2004). According to Portes and Rumbaut (2001), the ranking of social distance concurs by and large with a distinction in culture, physical appearance, and 
socioeconomic background. The more different migrants are from receiving societies, the lower the expected degree of socio-cultural integration. It is difficult to ascertain objectively which of the four origin countries (Morocco, Egypt, Senegal, and Ghana) are more culturally distant from southern European receiving societies. On the one hand, one might argue that from a religious point of view the three predominantly Muslim countries (Senegal, Morocco, and Egypt) are more different culturally than a predominantly Christian country such as Ghana. In northwest Europe, the Muslim identity of certain immigrant groups has sometimes been identified as a factor in explaining the "failure" to integrate (Thomson and Crul 2007), although this remains a highly contested issue. On the other hand, one might argue that Egypt and, particularly, Morocco are culturally closer to southern Europe and share centuries of social, cultural and economic exchange, occupation (in the case of the Spanish in northern Morocco), and the perhaps existence of shared Mediterranean cultural traits rooted in ancient history (cf. Gilmore 1982).

\section{Methods}

\subsection{Data}

This study draws on survey data generated by a research project "Push and Pull Factors of International Migration”. In 1997 surveys were carried out in five predominantly migrantsending countries in the Southern and Eastern Mediterranean region (Egypt, Morocco and Turkey) and in Sub-Saharan Africa (Ghana and Senegal) and in two predominantly migrantreceiving countries in the Mediterranean region (Italy and Spain). ${ }^{1}$ This survey was unique 
because it simultaneously collected pre and post-migration data, including data relating to the migration process itself.

Migrants from Egypt and Ghana (living in Italy) and Morocco and Senegal (living in Spain) participated in the survey. The survey focused on recent migration to southern Europe. Faceto-face interviews were conducted with each person between 18 and 65 years belonging to recent migrant households - that is, households in which at least one member has left the country of origin within the period of ten years preceding the survey. They were interviewed in their homes using structured questionnaires. Because of financial and logistic constraints, regionally representative rather than nationally representative sample designs were used. In Italy, a few cities and their provinces in two main geographical areas of the country were selected (Milan, Brescia, Bergamo and Modena in Northern Italy, Rome, Latina, Naples and Caserta in Central-Southern Italy); while in Spain the sample comprised five regions (Catalonia, Levant, Andalusia, Madrid and the Canary Islands). For more background information on sampling methods and representativeness, see Schoorl et al. (2000).

One recent migrant in each household was selected for a long interview. The criteria used to select this migrant, the so-called main migration actor (MMA), comprised the following: between 18 and 65 years old at the time of the interview, born in the country of origin, and 18 years or older at the time of the last migration from the country of origin. If more than one member of the household met these criteria, the migrant who had left first in the ten years preceding the survey was selected. Additional criteria were specified if several household members had migrated simultaneously. In the long individual MMA questionnaire, extensive data was gathered about the situation surrounding the last migration, the current situation in the country of destination, and the intentions for future migration. Our analyses are restricted 
to the 1707 male and 307 female MMAs for whom data on all relevant variables were available.

\subsection{Measuring instruments}

The degree of socio-cultural integration is the dependent variable in our analyses. The independent (predictor) variables are grouped in three categories: background characteristics, pre-migration factors and post-migration factors. Table 1 provides descriptive information on all variables, in total as well as separately for the four countries of origin.

TABLE 1 SOMEWHERE HERE

\section{Socio-cultural integration}

The survey data comprise seven different indicators of socio-cultural integration. In line with past studies (cf. Snel, Engbersen, and Leerkes 2006; van Niekerk 2007; Van Tubergen 2007), these indicators can be grouped under one of the three following dimensions of socio-cultural integration: (1) the degree of informal contact with native populations (objective, social dimension); (2) the extent to which migrants distinguish themselves from the native population with regard to language, habit, standards and values (objective, cultural dimension); and (3) the degree of identification with the own immigrant group (subjective). Instead of studying these dimensions and indicators separately, we constructed one index of socio-cultural integration. 
The first indicator is the extent to which migrants have social contacts with native populations. When asked with whom they met most frequently, respondents could opt for one of the following five categories: (1) mainly compatriots; (2) mainly native citizens; (3) with both groups equally; (4) mainly people from other countries; and (5) do not meet socially. Respondents who mainly keep company with native citizens are considered to be the most integrated (value: 2), followed by those who have social contacts with native citizens as well as compatriots (value: 1). The remaining respondents are considered to be the least integrated in this respect (value: 0).

The ethnic nature of migrants' circle of friends is the second indicator. This was proxied by the following question: "Do you have close friends among native citizens?", the reply categories being "no" (=0) and "yes" (=1).

The third indicator is participation in either native or foreign organizations. The respondents were asked whether they were active in four different types of organizations and, additionally, which was the dominant language spoken within each organization: (1) the language of the country of birth; (2) the language of the country of destination; or (3) another language. Respondents exclusively participating in one or more organizations were the destination country language is usually not spoken, are considered to be least integrated (value: 0 ). Respondents who were exclusively active in one or more organizations where Spanish or Italian is the official language are considered as most integrated (value: 2). The value of 1 is reserved for the remaining respondents.

Having a partner born in the receiving country $(0=\mathrm{no} ; 1=\mathrm{yes})$ is the fourth indicator of sociocultural integration. Because of the occurrence of polygamy especially among Senegalese 
migrants, a value of 1 is given to those who have at least one partner who is born in Spain or Italy.

The fifth indicator is fluency in the dominant language of the destination country. On the basis of data gathered on the ability to speak, read and write Spanish or Italian, we constructed a variable, ranging from 0 (unable to speak, read and write the language of country of destination) to 3 (able to speak, read and write the language of country of destination).

The sixth indicator is the degree of modernization regarding views on gender roles and (parent-child) relationships ${ }^{2}$. To gain insight into these issues, the respondents were presented with nine statements, viz. whether or not they think that "education is more important for boys than for girls" $(0=y e s, 1=$ no $)$, "children should obey their parents at all times" $(0=y e s)$, $1=$ no), "a young unmarried woman should be allowed to work outside the home" $(0=$ no, 1=yes), "a young woman and a young man should be allowed to go out together before they get married together" $(0=$ no, $1=y e s)$, "in financial matters the husband should take the decisions" ( $0=$ yes, $1=$ no), "a wife should obey her husband at all times, even when she thinks he is wrong" ( $0=y e s, 1=$ no), "a wife should take all the major decisions in the household if her husband moves abroad, and she stays behind?" $(0=$ no, $1=$ yes $)$, “the important decisions in the family should always be taken jointly by husband and wife" ( $0=$ no, $1=y e s)$, and whether they would approve of "a young unmarried women moving abroad to work there for a couple of years" ( $0=$ disapprove/neither approve nor disapprove, $1=$ approve $)$. The answers to these questions were subsequently summed. The score on this scale ranges from 0 to 9 , with a reliability coefficient of 0.71 (Chronbach's alpha). A high score is indicative of a higher degree of modernization regarding views on gender roles and (parent-child) relationships. 
The seventh and last indicator of socio-cultural integration is ethnic identification. This covers the subjective dimension and is based on the question to which country of population group respondent feel they most belong to. Answer categories included country of birth $(=0)$, country of destination $(=2)$, both countries $(=1)$, and another population group $(=0)$.

To obtain an overall index of socio-cultural integration, the seven indicators were summed after the range of each indicator has been revalued with a minimum of 0 and a maximum of 1 . As a result, the score on the index variable is at least 0 and at most 7 . The higher the score, the more the migrant is integrated in socio-cultural perspective. ${ }^{3}$ Table 1 shows that Senegalese migrants have the lowest level of socio-cultural integration, followed by Ghanaian migrants. The average level of socio-cultural integration among Moroccan and Egyptian migrants is identical. This does not resonate with the certain popular ideas representing the integration of immigrants from North Africa as particularly problematic or pointing out 'Islam' as a factor which would impede integration. Race seems a likely factor explaining the lower integration of sub-Saharan migrants. A further explanation can be that North African countries are considerably wealthier than sub-Saharan Africans such as Senegal and Ghana, and also score considerable higher on the human development index ${ }^{4}$. The more developed and modernized nature of North African societies is also likely to facilitate socio-cultural and economic integration. This also seems to challenge the hypothesis that migrants moving over greater geographical distances are likely to have more incentives to invest in human capital and will be more integrated, although this needs to be further tested into a multivariate setting. 


\section{Background characteristics}

Past studies (cf. Dagevos 2001; Dion and Dion 2004) have repeatedly shown that gender and ethnic differences affect integration in receiving societies. Therefore, we included variables indicating gender $(0=$ male, $1=$ female $)$ and country of birth. The latter variable is represented by three country dummy variables with Morocco as the reference category. There is a clear overrepresentation of male migrants in the four country-samples, reflecting the male dominated nature of labor migration from those countries. This especially holds for Egypt and Senegal. No more than 5 and 7 per cent, respectively, of the respondents is female. In the sample of Morocco and Ghana, one out of four and five, respectively, is female. This relatively high percentage seems to reflect increasing independent migration of Moroccan and perhaps also Ghanaian women who work in the domestic and other service sectors in southern Europe (de Haas 2007; Salih 2002), while migration from Egypt and Senegal still follows more traditional patterns.

\section{Pre-migration factors}

Five relevant pre-migration variables were included in the analysis. The first variable is the level of education, reflecting the highest level of education the respondents had completed by obtaining a qualification or diploma. Original scores were converted into three dummy variables: "primary", "secondary" and "higher than secondary", while "incomplete education" (i.e., less than primary or no education) is the reference category. With only a few exceptions, this variable can be considered as a proxy indicating the level of human capital gathered 
before the last migration, as the overwhelming majority (97\%) of the respondents completed their education in their country of birth.

Table 1 indicates large differences in educational attainment among the four immigrant groups. Egyptian migrants were the highest qualified at the time of their last move, followed by Ghanaian migrants. No less than 54 per cent of the Egyptian migrants had completed at least secondary school before they have left their country, while 30 percent obtained a higher education degree. Among Ghanaians, these percentages were 58 and 7, respectively. Senegalese migrants were the lowest qualified prior to their migration. Over half of them did not complete any education, 41 per cent completed primary school, and only 8 per cent of the Senegalese migrants had completed secondary or higher school. The high scores for Egyptian migrants might reflect that until recently most Egyptian migration to Europe and North America was predominantly a middle and upper class affair (Zohry and Harrell-Bond 2003). However, this seems much less the case for recent migration to southern Europe, where many migrants have migrated illegally.

The second variable is the main migration motive. Respondents were asked about their most and possibly second most important motive for their last move abroad. The large range of answer categories were recoded into three main groups: (1) economic motives (e.g., "financial needs", "improvement of working conditions" and "improvement of other living conditions", (2) relational motives (e.g., "to get married/just married", "to accompany/follow spouse" and "to accompany/follow parent(s)"), and (3) other, more "existential" motives (e.g., "dislike of living in the country of birth", "the lure of adventure", "the desire to go abroad" and "fear of war, civil conflict or prosecution"). Since many respondents only gave one reason for leaving their country of birth, our analyses are restricted to the main migration motive. The three 
categories of migration motivation were converted into dummy variables. "Other motives" were used as the reference category.

Table 1 indicates that economic reasons play a predominant role in the migration decisions. This partly reflects the unequal gender distribution in the sampling: women mention relational motives more frequently but are underrepresented in the survey. It is striking that Egyptian and Moroccan migrants report "other motives" more frequently than Ghanaian and Senegalese migrants. This might be related to the autocratic nature of the governments of these North African countries. A more oppressive regime might increase the desire to migrate irrespective of strictly economic reasons.

Information about the country of destination is the third variable. Respondents were asked whether they had information on ten specific aspects of the Italian or Spanish society prior to their migration as well as the sources of this information. These aspects particularly related to work (including the possibility of finding work and wage levels), welfare provisions (including unemployment/disability benefits and child allowances), and settlement (including the cost of living and the attitude towards foreigners). If the respondent had information on a particular aspect, the score was 1 . To obtain an indicator of degree of information, the scores on the 10 aspects were summed, resulting into an index running from 0 to 10 .

The sources of information were categorized in "informal" (i.e. information obtained from friends, relatives, tourists or foreign visitors) and "formal" (i.e. information presented by the mass media such as television, radio, newspapers and other written material and information gathered by schools/universities, agencies or other institutes, and because of a previous stay in the country of destination). On the basis of this information, the respondents were subdivided 
into three mutually exclusive categories: those who had information on at least one of the ten aspects in a formal way ( $0=$ no, $1=y e s)$, those who had obtained information exclusively through informal channels $(0=$ no, $1=y e s)$, and those who migrated without any information about Spain or Italy ( $0=$ no, $1=y e s$, being the reference category).

Table 1 reveals that Senegalese migrants were the least informed about the country of destination. Prior to arrival, only over one in three was conversant with any aspect of the Spanish society. Moroccan migrants were best informed, since 85 per cent of them did have information on one or more aspects of Spain. In addition, and in contrast to the other three immigrant groups, Moroccan migrants were often informed through formal channels. Again, this may be related to the geographical and the relative cultural proximity (in particular pertaining to language) to Spain, coinciding with the easy access to Spanish media, tourists and other sources of information. Another important factor is that the Moroccan migrant community in Spain is at least ten times larger than the other surveyed migrant communities. Around 2005, at least 490,000 registered Moroccan migrants were living in Spain against 32,000 Senegalese, while the numbers of registered Egyptian and Ghanaian migrants officially living in Italy were estimated at 59,000 and 34,000, respectively (de Haas 2007). The size of the Moroccan migrant population in Spain is likely to have facilitated the access to information through migrant networks.

The fourth variable is age at the time of migration, with scores ranging from 18 to 56 years. The mean age of the respondents at the time of their last migration was 28 years, which is largely in line with other empirical research. 
The last pre-migration variable is prior migration experience. Respondents were asked whether they had lived for at least one year in a foreign country and/or traveled abroad for a period of less than one year prior to their last migration $(0=$ no, $1=y e s)$. Table 1 indicates that earlier stays abroad were a relatively frequent phenomenon among the respondents in general and Senegalese in particular. It is not clear whether this mainly pertains to migration within West Africa or intercontinental migration.

\section{Post-migration factors}

Four variables pertaining to migrants' post-migration situation were included in the analysis. The first variable is working status, which was measured by questions on current paid employment, the number of hours worked per week, and, for those currently without worked, whether they ever worked in the country of destination. On the basis of these indicators three dummy variables were created, viz. "part-time job" (<32 hours per week), "full-time job", and "ever worked". Respondents who never worked since their last immigration are the reference group. Table 1 shows that the labor force participation is high among all immigrant groups, and especially among Egyptians and Senegalese: 88 per cent claimed they were currently working compared to 80 per cent among Moroccan and Ghanaian migrants.

In addition to working status the occupational status of the current job has also been considered as a determinant for economic integration. Respondents who were employed at the time of the interview were asked to describe their current occupation. The occupations were coded according to the International Standard Classification of Occupations (ISCO) and subsequently recoded into the International Socio-Economic Index of Occupational Status 
(ISEI; (Ganzeboom and Treiman 1996)), running from 16 (e.g., domestic workers, cleaners and launders, agricultural and fishery laborers) to 88 (medical doctors). The mean ISEI-score for the surveyed immigrant groups was attributed to those who did not currently work. No large differences between the four immigrant groups emerge. The mean occupational status is relatively low and similar across the surveyed immigrants groups, varying from an average of 27 for Moroccans and Senegalese to 30 for Egyptians.

The next post-migration variable is the length of stay, ranging from 0 to 10 years. The descriptive statistics in table 1 do not show large differences in the average length of stay between the respondents across the four surveyed immigrant groups.

The last relevant variable is the intention to migrate. Respondents were asked: "Do you intend to migrate?", with four different reply categories "no, want to stay in this country"; "yes, want to return to the country of origin"; "yes, want to migrate to another country", and "do not know”. Since only a few respondents intended to migrate to another than the origin country, this category was suppressed and lumped together with "yes, want to return to the country of origin" into a new category "wishes to migrate". Respondents intending to stay in Spain or Italy are the reference category. Table 1 shows that 48 percent of Moroccan migrants intend to stay in the destination country, which is significantly higher than among other immigrant groups. This might again reflect the more settled nature of Moroccan immigrant communities. Return intentions are highest among Ghanaians and, particularly Senegalese. About one third of all respondents are undecided about future return. It is important to note that the causality here is likely to go in two directions.

TABLE 2 SOMEWHERE HERE 


\section{Results}

To what extent are differences in socio-cultural integration among migrants attributable to pre and post-migration factors? Table 2 aims to provide an answer to this question by presenting the results of a step-wise regression analysis on the determinants of socio-cultural integration. Models 1, 2, and 3 subsequently incorporate the background characteristics (gender and country of origin), pre-migration factors, and post-migration factors. This sequence runs largely parallel to migrants' life stages or migration cycle. To facilitate comparison of the effect of the various variables on socio-cultural integration, we standardized the coefficients.

In Model 1, the two background characteristics country of origin and gender emerge as significant predictors. Gender and ethnicity alone explain 13 per cent of the variance (adjusted $\mathrm{R}^{2}$ ) in socio-cultural integration. Parallel to earlier observations, migrants born in Morocco and Egypt are more integrated than migrants from Ghana and, particularly, Senegal. Also female migrants appear to be significantly more integrated than men, which contradicts hypotheses that women from "patriarchical" cultural backgrounds would be more restricted to indoor life and hence, have less contact with native born.

The pre-migration factors are entered in Model 2. The strong increase in the explained part of the variance from 13 to 24 per cent indicates that pre-migration factors play an important role in socio-cultural integration processes. All pre-migration factors have a significant impact on migrant's socio-cultural integration and most albeit not always in the expected direction. First, in line with human capital theory, educational attainment before migration has the expected large and positive impact on socio-cultural integration. Nevertheless, the effect is not linear. 
Migrants who have completed secondary education are more integrated than those with primary education, and the latter are more integrated than unqualified migrants. However, no substantial differences in the degree of socio-cultural integration are found among migrants with secondary or higher levels of education. So, there may be "diminishing returns" of education on socio-cultural integration.

Migration motives also significantly affect socio-cultural integration, although not in the expected direction. Moving for "existential" reasons ("other" motives) has a positive effect on socio-cultural integration, while no significant differences are found between those whose migration was driven by either economic or relational motives. Further data analysis has indicated that the degree of socio-cultural integration is particularly low when "financial needs" or "improving the working conditions" were the main migration motives. This refutes the hypothesis that people who migrate to work will be in more frequent contact with native people and be more oriented towards receiving countries.

In line with our hypotheses, having access to pre-migration information about the situation in receiving countries has a significantly positive effect on socio-cultural integration. Furthermore, migrants who obtained information through official channels tend to be more integrated than migrants who have obtained information through informal channels. This corroborates the hypothesis that migrants obtaining information informally, do generally so through migrants networks, and tend to be more oriented towards their own (immigrant) community.

Age at the time of migration has the expected negative impact on socio-cultural integration. The effect is linear; additional analysis showed a non-significant effect of the squared age at 
the time of migration. Thus, the younger the migrants were at the time of their move, the more they are integrated. Finally, Model 2 shows that prior migration experience is an important determinant as well. As expected, migrants are on average more integrated if they had stayed abroad before the current stay.

Model 2 equally shows that introduction of the pre-migration factors do not erase the effects of country of birth and gender. On the contrary, while the effect of gender becomes slightly stronger, introduction of pre-migration factors now result in a significant difference between Moroccan and Egyptian migrants, whereas the effect was insignificant in Model 1. Also the differences with Ghanaian migrants increase, whereas differences with Senegalese decrease, although they remain statistically significant. This can be explained by the fact that Egyptian and Ghanaian migrants are relatively high-educated (see Table 1). In other words, if they would have the same level of education as migrants from Morocco, they would be less integrated. This corroborates the hypothesis that cultural and linguistic differences between Morocco and Spain are relatively small compared to the other three origin-by-destination combinations, and is the highest for Senegalese in Spain.

The post-migration factors are entered in Model 3, again leading also to a substantial increase of the explained variance, viz. from 24 to 32 per cent. However, this increase is somewhat smaller than the increase after the introduction of the pre-migration factors, suggesting that pre-migration factors included in the model are slightly more important as determinants of socio-cultural integration ${ }^{5}$. The introduction of post-migration factors does hardly affect the direction and significance of the effect of background and post-migration variables. The only exception is that the negative effect of economic and relational migration motives loses some strength and significance, although differences with Model 2 are rather minimal. The effect of 
education remains particularly strong, also in combination with work-related variables, which may reflect the attitudinal effect of education.

The analysis of the effects of labor market participation yields some important results. Being employed as such does not have a significant impact on socio-cultural integration. This goes against the hypothesis that work facilitates contacts with natives. However, this can easily be explained by the fact that few natives tend to work in many typical immigrant professions such as agriculture, construction and low-level service sector jobs. Many low skilled, typical immigrant jobs probably provide few opportunities and incentives to meet native workers, learn the language, and so on. Due to discrimination and other exclusion mechanisms migrants might have limited or no opportunities for upward professional mobility and might therefore get trapped in such jobs. In line with this hypothesis, we see that the occupational status of the current job has a highly significant effect on socio-cultural integration. Like educational attainment, occupational attainment appears to have the expected effect on the degree of socio-cultural integration: the higher the occupational status of the current job, the higher the level of socio-cultural integration. This is logical, as the likelihood of meeting natives is likely to increase with the occupational status of jobs.

However, unlike educational attainment, it is not possible to disentangle the direction of causality. Does a higher occupational status (an indicator of economic integration) make socio-cultural integration easier or does a stronger socio-cultural integration make an upward mobility on the labor market easier? It is likely that causality works in both directions, although with the current dataset we are not able to control for endogeneity in order to determine the "pure" effect of occupational status. 
According to our hypothesis, socio-cultural integration increases with period of residence.

Additional analysis suggests that this effect is more or less linear: the coefficient of the square of the duration of residence is negative but not significant. This is probably related to the fact that the sample only included people who migrated less than ten years ago.

Finally, Model 3 confirms the hypothesized negative effect of migration intentions on sociocultural integration. Migrants who express the intention to migrate and those who are not sure whether or not to migrate are generally less integrated than migrants intending to stay.

The question that immediately arises is to what extent these conclusions can be generalized. To answer this question, we repeated the regression analysis each of the four immigrant groups separately. The results presented in Table 3 show that the effect of the predictor variables are generally in the expected direction, although the strength of the effects varies considerably across the four immigrant groups and significance suffers because of a lower number of observations. Among all four migrants groups, there is a consistent pattern in which educational attainment prior to arrival, the duration of residence abroad, and migration intentions have a significant and positive effect on socio-cultural integration. An interesting deviation from this pattern is that among Ghanaian and Senegalese migrants the relation between schooling and socio-cultural integration seems to be curvilinear, with less positive returns of higher education on integration as compared to secondary education; there are no differences among Moroccan migrants with secondary and higher levels of education, while the effect is linear for Egyptian migrants. These differential effects of higher education on socio-cultural integration among different immigrant groups is difficult to explain with the current data set, but merits further exploration. 
The effect of migration motives largely corroborates the pooled data analysis, with migrants moving for other than economic and relational motives being the most integrated. Although significance suffers due to a lower number of observations than in the pooled regressions, the signs are in the expected direction. The only exception is the positive effect of migration for relational factors among Egyptian migrants, which is difficult to explain. The pre-migration degree of information has a positive effect on socio-cultural integration, although this effect is only significant for Moroccan and Ghanaian migrants. With the exception of Senegalese migrants, obtaining information from formal sources has a positive effect, although this effect is only weakly significant for Egyptian migrants.

Even more intriguing is the positive effect of female gender on socio-cultural integration, which is strongly significant among Moroccan and Ghanaian women. The coefficients are non-significant for Egyptians and Senegalese. This might be related to the fact that only 24 Egyptian and 31 Senegalese women were included in the survey, against 134 Moroccan and 118 Ghanaian women. So, when controlling for variables such as education, age, labor market integration and length of stay, women seem to be significantly more integrated on a sociocultural level than men. Moroccans were the only migrant group exhibiting a significant positive correlation between female gender and education. When running the regression for Moroccan migrants with gender as the only predictor variable, we found a significant ( $\mathrm{p}$ $<.001)$ coefficient of 0.18 . Including the education variables resulted in a further increase of the coefficient to 0.22 , and inclusion of the other pre-migration variables led to a further increase to 0.25 . For Ghanaian migrants, the significant coefficients were $0.18,0.19$ and 0.18 , respectively. 
The results of the partial regressions support the earlier findings that it is not so much the fact of working as such (having a full time job even has a negative effect among Moroccans), but the type of work (e.g., occupational status) that seems to matter, although results were only significant for Egyptians and Moroccans.

Finally, table 3 shows differences between the immigrant groups with regards to the explained variance (model fit) and the contribution by pre and post-migration factors. The model fit is better for North African migrants (29 and 31 percent for Moroccans and Egyptians) than for sub-Saharan migrants ( 24 and 16 percent for Ghanaians and Senegalese). The difference is possibly attributable to the greater variance in socio-cultural integration among the migrants from Morocco and Egypt compared to migrants from Ghana and Senegal.

Another dichotomy emerges with regard to the explanatory power of the pre and postmigration factors. While differences in socio-cultural integration among Moroccan and Senegalese migrants appear to be mainly determined by the pre-migration factors, postmigration factors are the best predictors for the variance in socio-cultural integration among Egyptian and Ghanaian migrants. This is difficult to explain on the basis of the current analysis.

TABLE 3 SOMEWHERE HERE 


\section{Conclusion}

The results of the pooled and immigrant-group specific data analysis are largely consistent with our theory-derived hypotheses on the determinants of socio-cultural integration. The analysis also exemplified that socio-cultural integration is determined to a considerable extent by the "baggage" migrants take along from their country of origin. Immigrants who were well-educated and well-informed prior to migration and who accumulated migration experience at a relatively young age achieve higher levels of socio-cultural integration. At the same time, the results suggest that migrants from Egypt and, particularly, Morocco are more integrated overall than migrants from sub-Saharan Africa, when controlling for individual pre and post-migration background characteristics. An obvious factor is that sub-Saharan migrants are more often confronted with racism and discrimination than north African migrants. Other explanatory factors might include unmeasured variables such as geographical and cultural proximity - despite a superficial religious split, Mediterranean societies also share a long common history and several cultural features - higher level of human development and modernization, and a higher degree of familiarity with European societies due to tourism, media, return migration and other exposure-increasing factors.

This study also generated some results which give reason to refute or amend some of our initial hypotheses. First, female gender has a strong, significantly positive and robust effect on socio-cultural integration. This refutes our hypothesis and defies stereotypes about the supposed passiveness, relative backwardness and tradition-boundness of female migrants from "patriarchal" developing countries. Although it is difficult to explain these findings convincingly on the basis of this dataset, there is a possible relation between this remarkable pattern and the nature of work immigrant women tend to do as opposed to men. Many African 
immigrant women in southern Europe are engaged in domestic and other care work in the informal sector (Anderson 2000; Anthias and Lazaridis 2000), which often brings them into direct and durable contact with their native employers and their children. This is more likely to engender personal relationships and lead to language acquisition than the agricultural and construction work many men tend to do in environments dominated by migrants with only superficial contacts with employers. A second explanation can be that female migrants are positively self-selected on unmeasured characteristics reflecting talent, ambition, independence and perseverance, even more so than men, because of the high social, cultural and economic obstacles women have to overcome to migrate. There is evidence that migration can be an escape for women from patriarchal structures and be a search for selfautonomy (Anthias and Lazaridis 2000), Therefore, the surveyed women are likely to be the more talented and ambitious women within origin societies.

The second striking result is that migrants who primarily migrate for economic motives and, to a lower extent, relational motives, exhibit lower level of socio-cultural integration than migrants who move for "existential" reasons. This seems to contradict evidence on economic integration, where economically motivated migrants showed a stronger labor market performance (van Tubergen, Maas, and Flap 2004). In parallel with the previous explanation for the higher integration of migrant women, what might play a role here is that migrants moving for reasons such as adventure, oppression and a dislike of the political and sociocultural environment in origin countries make a more conscious choice to move to another socio-cultural and political environment, to which they are subsequently likely to be more favorably predispositioned. This seems to particularly play a role among Moroccan and Egyptian migrants. 
Another result can help to further explain these patterns. The analyses consistently find that working status as such does not have any significant effect on socio-cultural integration, but occupational status has. This seems to corroborate earlier explanations linking women's relative successful socio-cultural integration to their specific occupational profile. It might also provide an explanation for the diverging effects of higher education on socio-cultural integration among different immigrant groups. Further research is needed to verify whether these differences can be explained by the different extent to which immigrant groups are able to capitalize on their education degrees by obtaining higher-level jobs, which is also likely to facilitate socio-cultural integration.

While educational attainment and length of stay have, unsurprisingly, the strongest effect on socio-cultural integration, this also holds for migration intention. Migrants who intend to return and those who are unsure about future migrant plans, are less integrated than migrants who have decided to settle, independent from other factors such as gender, age, length of stay and education. However, the causality is likely to be bi-directional, as migrants who face less obstacles in integrating, will also have less return migration intentions.

These findings are also relevant for current debates on (European) migration and integration policy. For instance, restrictive immigration policies which exclude (irregular) migrants from residency may eventually create new, marginalized classes of workers with limited options for upward socio-economic mobility because they will not have the opportunity to convert their human capital into careers. This might serve short-term economic interests, but seriously risks jeopardizing the common interest in the long-term economic and socio-cultural integration of migrants or might, at best, lead to downward assimilation. The results of this study seem to support earlier research that for the sake of economic prosperity and social cohesion, 
receiving societies have an interest in designing demand-driven immigration policies that benefit from the human capital they carry across border (for instance, by enforcing antidiscrimination policies, recognizing professional qualifications and selecting migrants for their specific skills), that give them a (gradual or phased) right to (permanent) residence, which also give opportunities to pursue professional careers. The findings presented here suggest that migrants who have a opportunity to settle and integrate in labor markets also exhibit a higher level of socio-cultural integration. 


\section{Endnotes}

${ }^{1}$ The project was funded by the European Commission, executed by Eurostat, and implemented by the Netherlands Interdisciplinary Demographic Institute (NIDI) in collaboration with researchers of local research institutes in the seven countries in question. ${ }^{2}$ By including this variable we do not want to suggest that such 'modern' family and gender norms are entirely accepted in destination societies. However, because it is assumed that, in general, the surveyed migrant groups adhere to more conservative or traditional values than non-immigrant population, a higher score on this variable can be seen as an indicator of integration.

${ }^{3}$ To explore the validity of our index scoring, we have also performed HOMALS analysis, and the nearly similar results reassure us that the index scoring of socio-cultural integration is appropriate.

${ }^{4}$ In 2005 the Human Development Index scores and the GDP per capita for the four origin countries were 0.646 and 1750 US\$ (Morocco), 0.708 and 1250 US\$ (Egypt), 0.553 and 450 US\$ (Ghana) and 0.499 and 700 US\$ (Senegal). Life expectancy at birth ranged from 70 and 71 for Morocco and Egypt to 57 for Ghana and 56 for Senegal, respectively (sources: World Development Indictors database and UNDP).

${ }^{5}$ The same conclusion can be drawn in case of reversed entry. The explained variance increases from 13 to 22 (introduction of the post-migration factors) and from 22 to 32 (introduction of the pre-migration factors) per cent, respectively. 


\section{References}

Alba, R. and V. Nee. 2003. Remaking the American mainstream: Assimilation and contemporary immigration. Cambridge MA: Harvard University Press.

Anderson, Bridget. 2000. Doing the Dirty Work? The Global Politics of Domestic Labour. London: Zed Books.

Anthias, Floya and Gabriella Lazaridis. 2000. "Gender and Migration in Southern Europe. Women on the Move." Pp. 263. Oxford, New York: Berg.

Aparicio, R. 2007. "The integration of the second and 1.5 generations of Moroccan, Dominican and Peruvian origin in Madrid and Barcelona." Journal of Ethnic and Migration Studies 33:11691193.

Becker, G.S. 1962. "Investments in Human Capital: A Theoretical Analysis." Journal of Political Economy 70:9-49.

Borjas, George J. . 1987. "Self-Selection and the Earnings of Immigrants." American Economic Review 77:531-53.

Bourdieu, Pierre. 1985. "The forms of capital." Pp. 241- 58 in Handbook of Theory and Research for the Sociology of Education, edited by J. G. Richardson. New York: Greenwood

Briggs, X. and de Souze. 2003. Bridging networks, social capital, and racial segregation in America. Cambridge, MA.: Faculty Research Working Papers Series no. RWP02-011. John F. Kennedy School of Government, Harvard University.

Castles, Stephen. 2006. "Guestworkers in Europe: A Resurrection?" International Migration Review 40:741-766.

Castles, Stephen, M. Korac, E. Vasta, and S. Vertovec. 2002. Integration: Mapping the Field. London: Home Office Online Report 28/03.

Chiswick, Barry R and Paul W. Miller. 2001. "A Model of Destination-Language Acquisition: Application to Male Immigrants in Canada." Demography 38:391-409.

Crul, M. and H. Vermeulen. 2003. "The future of the second generation: The integration of migrant youth in six European countries." International Migration Review 37:965-1144.

Dagevos, J. 2001. Perspectief op integratie: Over de sociaal-culturele en structurele integratie van etnische minderheden in Nederland. Den Haag: Wetenschappelijke Raad voor het Regeringsbeleid.

de Haas, Hein. 2007. "The Myth of Invasion: Irregular migration from West Africa to the Maghreb and the European Union." International Migration Institute, University of Oxford, Oxford.

Dion, Karen K. and Kenneth L. Dion. 2004. "Gender, immigrant generation, and ethnocultural identity." Sex Roles 50:347-355.

Doomernik, Jeroen. . 1998. The effectiveness of integration policies towards immigrants and their descendants in France, Germany and the Netherlands. Geneva: International Labour Organisation.

Ganzeboom, H.B.G. and D.J. Treiman. 1996. International Stratification and Mobility, File: Conversion Tools Utrecht: Department of Sociology.

Gilmore, David D. 1982. "Anthropology of the Mediterranean Area " Annual Review of Anthropology 11:175-205.

Givens, T. E. 2007. "Immigrant integration in Europe: Empirical research." Annual Review of Political Science 10:67-83.

Granovetter, Mark S. 1973. "The strength of weak ties." American Journal of Sociology 78:1360-1380.

Harris, John R. and Michael P. Todaro. 1970. "Migration, unemployment and development: A twosector analysis." American Economic Review 60:126-142.

Heckmann, F. 2005. Integration and Integration Policies. Bamberg: European Forum for Migration Studies.

Heckmann, F., H.W. Lederer, and S. Worbs. 2001. Effectiveness of national integration strategies towards second generation migration youth in a comparative European perspective. Final report to the European Commission. Bamberg: Emfs.

Kalmijn, M. . 1998. "Intermarriage and homogamy: Causes, patterns, trends." Annual Review of Sociology 24:395-421. 
King, Russell and Anastasia Christou. 2007. Cultural Geographies of Counter-Diasporic Migration: The Second Generation Returns 'Home'. Sussex Migration Working Paper No 45: University of Sussex.

King, Russell and Ronald Skeldon. forthcoming. "'Mind the Gap!' Integrating Approaches to Internal and International Migration." Journal of Ethnic and Migration Studies.

Kritz, Mary.M. and Hania Zlotnik. 1992. "Global interactions: Migration systems, processes and policies." Pp. 1-18 in International Migration System: A Global Approach, edited by M. M. Kritz, L. L. Lim, and H. Zlotnik. Oxford: Clarendon Press.

Meurs, D., A. Pailhe, and P. Simon. 2006. "The persistence of intergenerational inequalities linked to immigration: Labour market outcomes for immigrants and their descendants in France." Population 61:763-801.

Portes, A. 1998. "Social Capital: Its origins and applications in modern sociology." Annual Review of Sociology 24:1-24.

—. 2007. "Migration, development, and segmented assimilation: A conceptual review of the evidence." Annals of the American Academy of Political and Social Science 610:73-97.

Portes, A. and R.G. Rumbaut. 1990. Immigrant America: A portrait. Berkeley, CA: University California Press.

Portes, A., L. E. Guarnizo, and P. Landolt. 1999. "The study of transnationalism: pitfalls and promise of an emergent research field." Ethnic and Racial Studies 22:217-237.

Portes, A. and L. X. Hao. 2004. "The schooling of children of immigrants: Contextual effects on the educational attainment of the second generation." Proceedings of the National Academy of Sciences of the United States of America 101:11920-11927.

Portes, Alejandro. 2008. "Migration and Social Change: Some Conceptual Reflections." Pp. 73-97 in Keynote address to the conference on "Theorizing Key Migration Debates", Oxford University, July 1, 2008.

Portes, Alejandro and Rubén G. Rumbaut. 2001. Legacies: The Story of the Immigrant Second Generation. Berkeley, CA: University of California Press.

Putnam, R.D. 2000. Bowling alone: The collapse and revival of American community. New York: Simon \& Schuster.

Putnam, Robert D. 2007. "E Pluribus Unum: Diversity and Community in the Twenty-first Century " Scandinavian Political Studies 30:137-174.

Remmennick, Larissa 1999. "Women with a Russian accent' in Israel. On the gender aspects of Immigration." The European Journal of Women's Studies 6:441-461.

Ruhs, Martin. 2005. "The potential of temporary migration programmes in future international migration policy." Global Commission on International Migration Geneva.

Salih, R. . 2002. "Reformulating tradition and modernity: Moroccan migrant women and the transnational division of ritual space." Global Networks-a Journal of Transnational Affairs 2:219-231.

Schoorl, Jeanette, Liesbeth Heering, Ingrid Esveldt, George Groenewold, Rob van der Erf, Alinda Bosch, Helga de Valk, and Bart de Bruijn. 2000. Push and Pull Factors of International Migration: A Comparative Report. Luxembourg: Eurostat, European Communities.

Simon, P. . 2003. "France and the unknown second generation: Preliminary results on social mobility." International Migration Review 37:1091-1119.

Sjaastad, A.H. 1962. "The Costs and Returns of Human Migration." Journal of Political Economy 70:80-93.

Snel, E., G. Engbersen, and A. Leerkes. 2006. "Transnational involvement and social integration." Global Networks-a Journal of Transnational Affairs 6:285-308.

Thomson, Mark and Maurice Crul. 2007. "The Second Generation in Europe and the United States: How is the Transatlantic Debate Relevant for Further Research on the European Second Generation?" Journal of Ethnic and Migration Studies 33:1025-1041.

Todaro, Michael P. 1969. "A model of labor migration and urban unemployment in less-developed countries." American Economic Review 59:138-148.

van Londen, M., K. Phalet, and L. Hagendoorn. 2007. "Civic engagement and voter participation among Turkish and Moroccan minorities in Rotterdam." Journal of Ethnic and Migration Studies 33:1201-1226. 
van Niekerk, M. 2007. "Second-generation caribbeans in the Netherlands: Different migration histories, diverging trajectories." Journal of Ethnic and Migration Studies 33:1063-1081.

van Tubergen, F., I. Maas, and H. Flap. 2004. "The economic incorporation of immigrants in 18 western societies: Origin, destination, and community effects." American Sociological Review 69:704-727.

Van Tubergen, Frank. 2007. "Religious affiliation and participation among immigrants in a secular society: A study of immigrants in the Netherlands." Journal of Ethnic and Migration Studies 33:747-765.

Vertovec, S. 2004. "Migrant transnationalism and modes of transformation." International Migration Review 38:970-1001.

Zohry, A. and B. Harrell-Bond. 2003. "Contemporary Egyptian Migration: An Overview of Voluntary and Forced Migration " University of Sussex, Development Research Centre on Migration, Globalisation and Poverty, Sussex. 
Table 1. Descriptive statistics of the variables

\begin{tabular}{|c|c|c|c|c|c|c|c|c|c|c|}
\hline & \multicolumn{2}{|c|}{$\begin{array}{l}\text { Morocco } \\
(N=501)\end{array}$} & \multicolumn{2}{|c|}{$\begin{array}{c}\text { Egypt } \\
(N=450)\end{array}$} & \multicolumn{2}{|c|}{$\begin{array}{l}\text { Ghana } \\
(N=627)\end{array}$} & \multicolumn{2}{|l|}{$\begin{array}{l}\text { Senegal } \\
(N=436)\end{array}$} & \multicolumn{2}{|c|}{$\begin{array}{c}\text { Total } \\
(N=2014)\end{array}$} \\
\hline & $\%$ & $\mathrm{M}$ & $\%$ & $\mathrm{M}$ & $\%$ & $\mathrm{M}$ & $\%$ & $\mathrm{M}$ & $\%$ & $\mathrm{M}$ \\
\hline Socio-cultural integration $(0-7)$ & & 2.8 & & 2.8 & & 2.5 & & 1.7 & & 2.5 \\
\hline \multicolumn{11}{|l|}{ Background characteristics } \\
\hline \multicolumn{11}{|l|}{ Country of birth: } \\
\hline Morocco & & & & & & & & & 24.9 & \\
\hline Egypt & & & & & & & & & 22.3 & \\
\hline Ghana & & & & & & & & & 31.1 & \\
\hline Senegal & & & & & & & & & 21.6 & \\
\hline Female & 26.7 & & 5.3 & & 18.8 & & 7.1 & & 15.2 & \\
\hline \multicolumn{11}{|l|}{ Pre-migration } \\
\hline \multicolumn{11}{|l|}{ Level of education: } \\
\hline Incomplete education & 36.7 & & 7.1 & & 4.5 & & 51.4 & & 23.2 & \\
\hline Primary & 36.1 & & 9.1 & & 30.5 & & 41.1 & & 29.4 & \\
\hline Secondary & 21.2 & & 54.0 & & 57.9 & & 6.4 & & 36.7 & \\
\hline Above secondary & 6.0 & & 29.8 & & 7.2 & & 1.1 & & 10.6 & \\
\hline \multicolumn{11}{|l|}{ Motive of migration: } \\
\hline Economic motives & 83.4 & & 82.0 & & 90.9 & & 90.8 & & 87.0 & \\
\hline Financial needs & 22.8 & & 22.7 & & 24.6 & & 25.9 & & 24.0 & \\
\hline Improvement working conditions & 35.5 & & 35.8 & & 51.4 & & 56.7 & & 45.1 & \\
\hline Improvement other living conditions & 25.1 & & 23.6 & & 15.0 & & 8.3 & & 18.0 & \\
\hline Relational motives & 7.0 & & 6.9 & & 5.4 & & 6.4 & & 6.4 & \\
\hline Other motives & 9.6 & & 11.0 & & 3.6 & & 2.7 & & 6.5 & \\
\hline \multicolumn{11}{|l|}{ Type of information obtained: } \\
\hline No information & 15.4 & & 31.1 & & 32.0 & & 62.6 & & 34.3 & \\
\hline Information through informal channels & 42.9 & & 45.8 & & 41.5 & & 29.1 & & 40.1 & \\
\hline Information through formal channels & 41.7 & & 23.1 & & 26.6 & & 8.3 & & 25.6 & \\
\hline $\begin{array}{l}\text { Number of issues about which } \\
\text { information obtained }(0-10)\end{array}$ & 3.0 & & 2.3 & & 1.7 & & 1.2 & & 2.1 & \\
\hline Age at time of migration (18-56) & 28.5 & & 27.3 & & 27.3 & & 29.4 & & 28.0 & \\
\hline Prior migration experience & 31.7 & & 28.4 & & 25.5 & & 44.3 & & 31.8 & \\
\hline \multicolumn{11}{|l|}{ Post-migration } \\
\hline \multicolumn{11}{|l|}{ Working status: } \\
\hline Part-time job & 11.0 & & 8.7 & & 12.6 & & 7.8 & & 10.3 & \\
\hline Full-time job & 69.5 & & 79.3 & & 66.3 & & 80.7 & & 73.1 & \\
\hline Ever worked & 11.1 & & 6.0 & & 16.1 & & 7.1 & & 10.7 & \\
\hline Never worked & 8.3 & & 6.0 & & 5.0 & & 4.4 & & 5.9 & \\
\hline Occupational status current job (16-88) & 27.4 & & 29.8 & & 28.5 & & 26.7 & & 28.1 & \\
\hline Length of stay (in years: $0-10$ ) & 5.4 & & 6.2 & & 5.6 & & 5.3 & & 5.6 & \\
\hline \multicolumn{11}{|l|}{ Migration intention: } \\
\hline Yes & 22.0 & & 29.8 & & 32.2 & & 42.0 & & 31.2 & \\
\hline Do not know & 29.7 & & 35.6 & & 34.1 & & 29.1 & & 32.3 & \\
\hline No & 48.3 & & 34.6 & & 33.7 & & 28.9 & & 36.5 & \\
\hline
\end{tabular}


Table 2. Determinants of the degree of socio-cultural integration among migrants in Spain and Italy (standardized regression coefficients, $N=2014$ )

$\begin{array}{llll}\text { Model: } & 1 & 2 & 3\end{array}$

\section{Background characteristics}

Country of birth:

$\begin{array}{lll}0.00 & -0.11 * * * & -0.13 * * * \\ -0.11 * * * & -0.17 * * * & -0.17 * * * \\ -0.36 * * * & -0.26 * * * & -0.23 * * * \\ & & \\ 0.11 * * * & 0.13 * * * & 0.15 * * *\end{array}$

Senegal

$\begin{array}{lll}0.11^{* * *} & 0.13 * * * & 0.15 * * *\end{array}$

Female

\section{Pre-migration}

Level of education:

Primary

Secondary

Above secondary

(ref. incomplete education)

Motive of migration:

Economic motives

Relational motives

(ref. other motives)

Degree of information obtained

Type of information obtained:

Information through formal channels

(ref. subjective information through informal

channels or no information)

Age at time of migration

Prior migration experience

\begin{tabular}{|c|c|}
\hline $0.13^{* * *}$ & $0.14 * * *$ \\
\hline $0.28 * * *$ & $0.28 * * *$ \\
\hline $0.27 * * *$ & $0.26^{* * *}$ \\
\hline$-0.12 * * *$ & $-0.10 * * *$ \\
\hline$-0.07 * *$ & $-0.06^{*}$ \\
\hline $0.06 * *$ & $0.06^{* *}$ \\
\hline $0.07 * *$ & $0.07 * *$ \\
\hline$-0.11 * * *$ & $-0.14 * * *$ \\
\hline $0.08^{* * * *}$ & $0.07 * * *$ \\
\hline
\end{tabular}

\section{Post-migration}

Working status:

Part-time job

Full-time job

Ever worked

0.01

0.03

(ref. never worked)

Occupational status current job

0.01

Length of stay

$0.11 * * *$

$0.19 * * *$

Migration intention:

Yes

$-0.14 * * *$

Do not know

$-0.18 * * *$

(ref. no intention)
Adjusted R 2
0.13
0.24
0.32
Change adjusted $\mathrm{R}^{2}$
$0.13 * * *$
$0.11^{* * *}$
$0.08^{* * *}$

$* * * p<.001 ; * * p<.01 ; * p<.05$ 
Table 3 Determinants of the degree of socio-cultural integration among migrants in Spain and Italy by country of origin (standardized regression coefficients)

$\begin{array}{cccc}\begin{array}{c}\text { Morocco } \\ (N=501)\end{array} & \text { Egypt } & \text { Ghana } & \text { Senegal } \\ & (N=450) & (N=627) & (N=436)\end{array}$

\section{Background characteristics}

\section{Female}

\section{Pre-migration}

Level of education:

\section{Primary}

Secondary

Above secondary

(ref. incomplete education)

Motive of migration:

Economic motives

Relational motives

(ref. other motives)

Degree of information obtained

Type of information obtained:

Information through formal channels

(ref. information through informal

channels or no information)

Age at time of migration

Prior migration experience

\section{Post-migration}

Working status:

Part-time job

Full-time job

Ever worked

(ref. never worked)

Occupational status current job

Length of stay

Migration intention

Yes

Do not know

(ref. no intention)

Adjusted $\mathrm{R}^{2}$ excl. post-migration factors

0.24

0.31

0.10 *

$0.22 * * *$

$0.23 * * *$

$0.16^{* * *}$

$0.29 * *$

$0.38 * * *$

0.12

$0.23^{* *}$

$0.19 * *$

$-0.11 *$

$-0.06$

$-0.03$

$0.12 *$

$-0.17 * *$

$-0.12 *$

$-0.24 * *$

$0.14^{* *}$

0.04

$0.12 * *$

0.02

0.02

$0.10 *$

0.05

$-0.02$

$-0.24 * * *$

$0.21 * * *$

$-0.16 * * *$

0.08

$-0.03$

0.05

$-0.17 * *$

$-0.08$

$-0.07$

$-0.17 *$

$-0.02$

0.10 *

$0.16^{* * *}$

$0.17 * * *$

$-0.12 * *$

$-0.17 * * *$

$-0.25 * * *$

$-0.29 * * *$

-0.10 *

0.13

0.11

0.11

Adjusted R²

*** $p<.001 ; * * p<.01 ; * p<.05$ $\begin{array}{lll}0.29 & 0.23 & 0.16\end{array}$
0.06

0.02

0.02

0.04

$0.15^{* *}$

$-0.16^{* *}$

$-0.21 * * *$ 